\title{
Cortisol in hair: a comparison between wild and feral cats in the north-eastern Alps
}

Marcello Franchini ${ }^{1}$, Alberto Prandi ${ }^{1}$, Stefano Filacorda ${ }^{1,{ }^{*}}$, Eva Nilanthi Pezzin ${ }^{2}$, Yannick Fanin $^{1}$, Antonella Comin ${ }^{1}$

${ }^{1}$ Dipartimento di Scienze Agroalimentari, Ambientali e Animali, Via Sondrio 2/A, 33100, Udine, Italy.

${ }^{2}$ Dipartimento di Biologia, Via Ugo Bassi 58/B, 35131, Padova, Italy.

"Corresponding author: Stefano Filacorda - e-mail: stefano.filacorda@uniud.it, tel: 0432558192

\section{Abstract}

The quantification of glucocorticoid metabolites in hair is a non-invasive tool that provides important information regarding the endocrine status and represents a valuable method for studying potential stressors that may affect carnivores under both natural and non-natural conditions. Cortisol is the main glucocorticoid hormone of the hypothalamic-pituitary-adrenal gland axis and is considered a standard stress indicator for animal welfare. The current study aimed to compare cortisol levels extracted from hair of both dead, frozen European wildcats (Felis silvestris silvestris) and living feral individuals (Felis silvestris catus) living in different environmental conditions. The results obtained revealed that wild individuals exhibited a significantly $(p<0.001)$ higher cortisol concentration $(\mathrm{n}=15$, mean $\pm \mathrm{sd}=8.91 \pm 4.48 \mathrm{pg} / \mathrm{mg})$ than feral ones $(\mathrm{n}=10$, mean $\pm \mathrm{sd}=3.57 \pm 1.25 \mathrm{pg} / \mathrm{mg})$, probably as a result of both the physiological and/or environmental factors to which each subspecies was subject. This is the first study in which cortisol concentrations have been compared within the Felis silvestris subspecies, thus enriching the scarce information available for the Felidae. Nevertheless, further research is needed to better understand the various physiological and ecological factors affecting the adrenocortical activity of species or populations living in different environmental contexts.

Keywords: wildcat, feral cat, Felis silvestris, hair cortisol, adrenocortical activity.

7


We wish to thank both the staff working for the Province of Gorizia and the Natural History Museums of Pordenone, Udine, and Trieste for the hair samples provided. Furthermore, the authors are indebted to all the wildlife technicians, interns, and volunteers involved in the collection of field data. 


\section{Introduction}

The ability of an organism to adapt to changes in environmental conditions has been receiving increased attention in recent years (Koolhaas et al. 1999; Janczak et al. 2003; Natoli et al. 2005; David et al. 2011; Ruiz-Gomez et al. 2011; Montiglio et al. 2012; Dingemanse and Reale 2018). Abiotic and biotic changes are common within the environment, and animals may respond through temporal variation in their vital rate and/or an alteration in their physiological response (Darlington et al. 1990). The activity of the hypothalamic-pituitary-adrenal (HPA) gland axis leads to the release of glucocorticoids (GCs), which are commonly used as indicators of physiological stress (Wingfield and Romero 2001; Wikelski and Cooke 2006). When animals are subjected to a stressor, the hypothalamus releases corticotropin-releasing hormones (CRHs) which signal to the adrenal cortex to release steroid hormones (such as GCs) to overcome stressful situations (Sapolsky et al. 2000) and restore homeostasis (Möstl and Palme 2002). This said, prolonged exposure to stressors may lead to chronic GC accumulation leading to chronic stress (Romero 2004) which is detrimental. Chronic stress negatively affects individuals' fitness in terms of the depression of immune responses, reduced reproductive success and growth suppression (Romero 2004). The quantification of glucocorticoid metabolites is a non-invasive tool that provides important information regarding endocrine status, and is a valuable method to study the potential stressors that may affect carnivores under natural conditions (Barja et al. 2007; Sheriff et al. 2011; Piñeiro et al. 2012; Schell et al. 2017). Cortisol is the main glucocorticoid hormone of the HPA gland axis and is considered the standard stress indicator for animal welfare (Mormède et al. 2007). Indeed, despite the various autonomic and endocrine responses that occur when an organism faces a stressful situation, cortisol has become commonly known as the stress hormone. As part of the stress response, cortisol acts on various metabolic pathways providing energy during a stressful situation. Cortisol's role in the endocrine system is metabolic however, and it is also released in response to arousal situations such as during sexual activity (Hamilton et al. 2008). Cortisol levels can be measured using both invasive (e.g. blood) and non-invasive methods in faecal samples (Dehnhard et al. 2001; Millspaugh et al. 2002; Huber et al. 2003; Ashley et al. 2011), urine (Rehbinder and Hau 2006), milk (Gygax et al. 2006) and saliva (Negrão et al. 2004). However, all these methods provide information in relation to short-term cortisol variations (within 12-24 h) (Sheriff et al. 2011; Russell et al. 2012). Hair and fur have been recognized as a relatively stable matrix that does not decompose as rapidly as other body fluids or tissues (Balíková 2005), and in which the incorporation of blood-borne hormones occurs through their passive diffusion from blood capillaries present on the basement membrane during its active growth phase (Pragst and Balikova 2006). These hormones accumulate over a period of weeks or months (Davenport et al. 2006; Macbeth et al. 2010) and may remain detectable for long periods (Kintz et al. 2006; Webb et al. 2010) as the cortisol in hair is unaffected by variations in circadian hormone or by factors that induce short-term variations (Caslini et al. 2016). In this sense, measuring cortisol accumulating in hair or fur represents a valuable method to trace rates of long-term stress in both domestic (Comin et al. 2011, 2013, 2014; Peric et al. 2016, 2017, 2018; Stradaioli et al. 2017) and wildlife species (Bechshøft et al. 2011, 2012, 2015; Caslini et al. 2016; Weisser et al. 2016; Prandi et al. 2018). However, the technique's main limit is related to hair's slow growth rate which does not permit fine monitoring over short periods as it does not reflect daily or hourly fluctuations in circulating hormones (Koren et al. 2002). Although the dynamics of stress physiology have been studied in a range of taxa, to date, limited information is available concerning adrenal activity variations in response to environmental conditions, life-history stages or among individuals (Boonstra 2004; Romero 2004; Palme 2005; Wielebnowski and Watters 2007). GC concentration has been shown to change in relation to sex, age class, day time, season and reproductive status (Ziegler and Snowdon 1995; Gardiner and Hall 1997; Cavigelli 1999; Romero 2002; Weingrill et al. 2004; Dantzer et al. 2010; Fanson et al. 2012). Furthermore, an existing 
difference in terms of circulating GC concentrations among species has been demonstrated (Roth et al. 2001). Cortisol level comparisons among species or subspecies have received little attention in recent years, especially as far as the Felidae (Fanson et al. 2012; Narayan et al. 2013; Naidenko et al. 2011, 2019) are concerned, and information relating to adrenocortical activity expression in the European wildcat (Felis silvestris silvestris) is still limited and mostly focused on faecal cortisol analyses (Piñeiro et al. 2012, 2015). Indeed, to the best of our knowledge, there are no previous studies aimed at assessing the potential differences in GC concentrations between wild and feral cats (Felis silvestris catus). The European wildcat is a medium-sized carnivore widely but patchily distributed throughout Europe (Driscoll and Nowell 2010; Lozano and Malo 2012). It is a protected species listed within the Annex IV of the European Union Council Directive 92/43/EEC, which states that a strict protection regime must be applied across its entire natural range within the EU, both within and outside Natura 2000 sites. The conservation of this carnivore requires considerable effort due to its elusive behaviour, low population density and sensitivity toward habitat loss and human persecution (Yamaguchi et al. 2015; Apostolico et al. 2016). Three fragmented populations are present along the Italian peninsula (thus, excluding those on Sardinia and Sicily): one in each of central and southern Italy, respectively, and another in the Eastern Alps, which is perhaps conjunctive with the Slovenian and Croatian populations (Mattucci et al. 2013). In Friuli Venezia Giulia the species is well distributed, particularly in the Julian Pre-Alps, but has also exhibited a positive dispersal trend even into lowland areas (Lapini 2006). The tendency to expand both north and southwards seems to have begun in the middle of $20^{\text {th }}$ century, presumably favoured by two factors: $(i)$ the recent spread of woodland in both the Alps and the Karst, and (ii) the legal protection of the species in 1977 (N. L. 968/1977), subsequently confirmed and individuals (range: 148-296) (Lapini 2006).

Understanding the mechanisms of adrenal activity is essential to provide important insights into comparative physiology. Comparing HPA gland axis activity between species or subspecies living in different environmental settings may help to cast light on the complex normative patterns of GC expression in various situations, for instance, establishing basic information regarding adrenal activity in endangered species living in both wild and captive conditions, providing a foundation for future studies on stress physiology and may help to enhance $e x$-situ and in-situ management plans (Fanson et al. 2012). Moreover, the comparison of physiological activities between subspecies or populations living in different environmental contexts (i.e. wild and feral populations) may be useful in understanding the complexity of ecological factors (e.g. active movements, hunting, competition) involved in the higher metabolic levels recorded in wild animals (Naidenko et al. 2011).

The present pilot study sought to compare hair cortisol concentrations (HCCs) between wild and feral cats. Our hypothesis was that the two subspecies had different physiological responses and were subject to different environmental pressures. Thus, we predicted that the HCCs recorded in wild individuals would be different compared to those measured in feral ones.

\section{Materials and Methods}

\subsection{Study area}

Friuli Venezia Giulia is the north-easternmost Italian Region, which borders Austria to the north and Slovenia to the east. It is bordered to the south by the Adriatic Sea, while to the west it adjoins the Veneto Region (Fig1). Its climate is characterized by an average annual temperature of about $14.5^{\circ} \mathrm{C}$ with abundant precipitation (as much as 3,000 
$\mathrm{mm}$ /year in the Pre-alps), especially during autumn ( 1,200-1,400 mm/year). Habitat varies with location, with forests and open habitats common in Alpine and pre-Alpine territories, while agricultural lands are most abundant in lowland areas (the official website of Friuli Venezia Giulia region, n.d.).

\subsection{Data collection}

Hair samples from 15 road-kill wildcats (11 males and four females) and ten living feral individuals (eight males and two females) were included in the present study. The wildcat carcasses were opportunistically collected between 2006 and 2014 and deep-frozen to prevent decay. Five individuals (four males and a female) were collected during the mating season (from January to March) while ten (seven males and three females) were found outside the mating season, of which three (a male and two females) were found during the period (from April to May) (Killshaw 2011) when the kittens are born. Hair samples belonging to the Felis silvestris catus subspecies were collected from individuals living in colonies near urban settlements (small villages), in which contacts with humans were solely related to feeding behaviour. Nevertheless, no information concerning either the season or year of data collection was available. Furthermore, no information regarding their health status or whether the animals were pregnant or not were obtained for either subspecies, though no evident signs of reproduction were noted. Hair samples were removed from the scruff of the neck of both wild and feral cats for two reasons: $(i)$ it represents an area with less contamination by external agents such as saliva and/or soil and (ii) has a uniform hair growth rate. Finally, the samples collected were stored in paper envelopes.

\subsection{Data analysis}

The attribution to the subspecies silvestris was carried out using the system proposed by Ragni and Possenti (1996), modified by Ballesteros-Duperón et al. (2015). Potential hybrids and feral cats were considered as a single group because hair samples were collected from individuals living within the same colonies. Using QGIS Software (version 2.18) we applied a buffer with a radius of $1,820 \mathrm{~m}$ for each point representing the recovery coordinates of each roadkilled wildcat. The choice to apply such a buffer was made to reproduce the average home-range size of a wildcat according to Anile et al. (2017). Within the buffer area, we calculated a habitat suitability (HS) value, ranging from 0 (unsuitable habitat) to 100 (optimal habitat), by multiplying the percentage of landscape (PLAND) calculated for each habitat with a habitat suitability index (HSI) varying from 0 to $1(0=$ unsuitable habitat; $0.33=$ little suitable habitat; 0.66 = suitable habitat; 1 = optimal habitat), randomly defined. Based on the habitat legend obtained from the attribute table of the shapefile named the "Carta della Natura del Friuli Venezia Giulia (2007)" and freely downloadable from the Regional IRDAT website, we determined the suitability or unsuitability of each habitat following Lozano et al. (2003), Lozano (2010), Sarmento et al. (2006), and Klar et al. (2008). Finally, we extracted an index of anthropic pressure (IAP) within each buffer, obtained from the attribute table of the "Carta Natura" shapefile and calculated it following the method proposed by Angelini et al. (2009).

\subsubsection{Cortisol radioimmunoassay}

Cortisol extraction was carried out using a radioimmunoassay protocol. Strands of hair were washed in $3 \mathrm{~mL}$ isopropanol and dried. Unminced hair $(5 \mathrm{mg})$ was extracted in a glass vial using $3 \mathrm{~mL}$ of methanol. The vials were then incubated at $37^{\circ} \mathrm{C}$ for $18 \mathrm{~h}$. After this the methanol was decanted into a separate vial from which it was evaporated to dryness. Next, the liquid in the vial was evaporated to dryness at $37^{\circ} \mathrm{C}$ under an airstream suction hood. The remaining residue was dissolved in $0.35 \mathrm{~mL}$ of phosphate-buffered saline (PBS), $0.05 \mathrm{M}$, pH 7.5 (RIA buffer). The cortisol in the 
hair was measured using a solid-phase microtitre RIA procedure. In brief, a 96-well microtitre plate (OptiPlate, PerkinElmer Life Science, Boston, MA, USA) was coated with goat anti-rabbit $\gamma$-globulin serum, diluted 1:1000 in 0.15 mM sodium acetate buffer, $\mathrm{pH}$, and incubated overnight at $4^{\circ} \mathrm{C}$. The plate was washed twice with RIA buffer, $\mathrm{pH} 7.4$, and incubated overnight at $4^{\circ} \mathrm{C}$ with $200 \mu \mathrm{L}$ of the anti-cortisol serum diluted 1:20000. The rabbit anti-cortisol antibody used was obtained from Biogenesis (Poole, UK) as described by Leboulenger et al. (1982). The cross-reactivities of this antibody with other steroids are as follows: cortisol $100 \%$, corticosterone $1.8 \%$ and aldosterone $<0.02 \%$. After washing the plate with RIA buffer, standards (5 - 200 pg/well), a quality control extract, the test extracts and tracer (Hydrocortisone (Cortisol, [1,2,6,7-3H (N)]-), Perkin-Elmer Life Sciences, Boston, MA, USA) were added, and the plate was incubated overnight at $4^{\circ} \mathrm{C}$. The bound hormone was separated from the free hormone by decanting the extract and washing the wells in RIA buffer. After the addition of $200 \mu \mathrm{L}$ scintillation cocktail, the plate was counted on a beta-counter (Top-Count, Perkin-Elmer Life Sciences, Boston, MA, USA). The intra-assay and inter-assay coefficients of variation were $3.6 \%$ and $9.8 \%$, respectively. The assay sensitivity (defined as the hormone concentration resulting in a displacement of the labeled hormone at least 2 standard deviations from maximal binding) was 1.23 pg/well. To determine the comparability between cortisol standards and endogenous cortisol in cats, hair samples containing high concentrations of endogenous cortisol were serially diluted in $0.05 \mathrm{M} \mathrm{PBS,} \mathrm{pH} \mathrm{7.5.} \mathrm{The} \mathrm{relationship}$ between hair cortisol concentrations and the standard cortisol curve, determined through linear regression, was linear: the correlation coefficient (r) was 0.99 and the model was provided by the equation $y=0.9796 x+1.68$.

\subsubsection{Statistical analysis}

Statistical analysis was performed through R Software (version 3.5) and the alpha value was set at 0.05. Data were analyzed in terms of HCC in which subspecies and sex were considered as independent variables and cortisol concentration as a dependent variable.

To determine the effect of subspecies and sex on HCC, Generalized Linear Models (GLMs) following Zuur et al. (2009) were used in which the family distribution of the dependent variable was assessed using the $\mathrm{R}$ package “fitdistrplus". Models ranking was done based on the Akaike's Information Criterion corrected (AICc) to best fit with reduced sample sizes.

\section{Results}

The average PLAND value calculated within each buffer area (radius $=1,820 \mathrm{~m}$ ) revealed that habitat was mainly composed of forests and semi-natural areas (47.03\%) followed by agricultural areas (34.95\%), artificial surfaces $(16.67 \%)$, water bodies $(0.76 \%)$ and wetlands $(0.59 \%)$. The average calculated HS index was equal to 51.53 revealing a habitat less suitable for the wild subspecies, while the IAP was equal to 0.66 indicating a notable anthropic pressure in each area.

From the model ranking using the AICc value as reference parameter, we discerned that the best model was the one in which only the effect of the "subspecies" variable was considered (Tab1). Results obtained showed a significant difference $(p<0.001)$ between subspecies. Cortisol concentrations measured in the hair of frozen wildcats $(\mathrm{n}=15)$ ranged from 3.90 to $19.30 \mathrm{pg}$ cortisol/mg hair (mean $\pm \mathrm{sd}=8.91 \pm 4.48 \mathrm{pg} / \mathrm{mg}$ ), while those in live feral individuals (n $=10$ ) varied from 2.20 to $6.50 \mathrm{pg}$ cortisol $/ \mathrm{mg}$ hair (mean $\pm \mathrm{sd}=3.57 \pm 1.25 \mathrm{pg} / \mathrm{mg}$ ) (Tab2; Fig2). Cortisol levels encountered in wild males $(n=11)$ ranged from 4.30 to $19.30 \mathrm{pg}$ cortisol/mg hair $($ mean $\pm \mathrm{sd}=9.69 \pm 4.81 \mathrm{pg} / \mathrm{mg})$ while those in wild females $(\mathrm{n}=4)$ varied from 3.90 to $10.50 \mathrm{pg}$ cortisol $/ \mathrm{mg}$ hair $($ mean $\pm \mathrm{sd}=6.78 \pm 2.87 \mathrm{pg} / \mathrm{mg})$ 
(Tab3; Fig3). Cortisol concentrations measured in feral males $(\mathrm{n}=8)$ ranged from 2.20 to $6.50 \mathrm{pg}$ cortisol $/ \mathrm{mg}$ hair (mean $\pm \mathrm{sd}=3.76 \pm 1.33 \mathrm{pg} / \mathrm{mg}$ ) while those in feral females $(\mathrm{n}=2$ ) varied from 2.50 to $3.20 \mathrm{pg}$ cortisol $/ \mathrm{mg}$ hair (mean $\pm \mathrm{sd}=2.81 \pm 0.50 \mathrm{pg} / \mathrm{mg}$ ) (Tab3; Fig3). Nevertheless, no significant difference was found between sexes in either wild or feral individuals.

\section{Discussion}

\subsection{Differences in cortisol levels between wild and feral cats}

Using a radioimmunoassay protocol, we were able to detect good levels of hair cortisol in both subspecies. In wild individuals, we obtained an average ( \pm sd) value of $8.91 \pm 4.48 \mathrm{pg}$ cortisol $/ \mathrm{mg}$ hair, while in feral ones we recorded an average ( \pm sd) level corresponding to $3.57 \pm 1.25 \mathrm{pg}$ cortisol/mg hair. It is important to specify that road-kill events do not affect hair cortisol accumulation for two reasons: $(i)$ cortisol enters the hair shaft through passive diffusion from blood vessels and thus requires a certain amount of time, (ii) the freezing process blocks cortisol accumulation in hair when the blood freezes. Therefore, the potential negative effect of the freezing process can be excluded as the cholesterol substrate inside the hair prevents cortisol degradation (Prandi unpub. data). Average HCC measured in feral cats was similar to that one obtained by Accorsi et al. (2008) in domestic cats ( $3.32 \pm 0.27 \mathrm{pg}$ cortisol/mg HCC). This said, the levels measured when compared with those recorded in wild individuals was remarkable, a significant difference being found between HCCs in wild and those in feral cats. Because of the existence of species-specific differences in the secretion of metabolic hormones, the radio-immunological protocols used during the extraction of certain groups of steroid hormones should be performed separately, even in the case of phylogenetically-related species (Palme et al. 1996; Schwarzenberger et al. 1996; Schwarzenberger and Palme 1997; Graham et al. 2001; Möstl and Palme 2002; Young et al. 2004; Palme 2005; Berger et al. 2006; Heistermann et al. 2006). An example of how different reproductive and endocrine physiology may be, even among phylogenetically close species, was demonstrated by endocrine studies performed on four rhino species: the white rhino (Ceratotherium simum), black rhino (Diceros bicornis), Indian or greater one-horned rhino (Rhinoceros unicornis) and the Sumatran rhino (Dicerorhinus sumatrensis). Throughout the use of faecal, urine and saliva steroid analysis, authors showed that not one of the four species exhibited reproductive cycles of similar length. What was more, faecal steroid metabolites excreted varied considerably underling the necessity to carry out species-specific endocrine tests (Roth et al. 2001; Schwarzenberger 2007).

Hair cortisol levels comparison between subspecies has received little attention in recent years, especially as far as the Felidae are concerned (Narayan et al. 2013, Naidenko et al. 2019). For instance, Narayan et al. (2013) compared Faecal Cortisol Metabolites (FCMs) in captive Bengal (Panthera tigris tigris) and Sumatran (Panthera tigris sumatrae) but no significant difference in terms of cortisol levels between subspecies was found. However, the main differences with our study were firstly related to the matrix used for cortisol extraction and, secondly, to the captive condition of the two tiger populations considered which may have affected faecal cortisol concentrations differently. Despite faecal-based immunoassay being considered one of the most valuable methods for mammals stress assessment, especially for endangered and managed populations, due to its non-invasiveness (Schatz and Palme 2001; Young et al. 2004; Palme 2005; Keay et al. 2006; Bayazit 2009) it presents some limitations given that FCMs analysis provides a pooled value of GC activity over the short term while HCCs provide a measure of past long-term HPA gland axis activity which cannot be obtained using other analyses (Lafferty et al. 2015). The effect of captivity on GC concentration comparing wild and captive animals has been examined but the results obtained are controversial. For instance, Naidenko et al. (2011) 
obtained a significant difference in terms of HPA gland axis activity between wild and captive Amur tigers (Panthera tigris altaica) where wild specimens, probably due to unfavourable environmental conditions in which they lived, showed significantly higher cortisol levels compared to captive ones. Contrariwise, Fanson et al. (2012) showed that captive Canada lynx (Lynx canadensis) had higher FGM concentrations than wild lynx. In our case, we could not perform a comparison with such studies as a feral existence is not the same as captivity. Nevertheless, differences recorded in terms of HCCs between wild and feral cats may be related to various factors. The first explanation could be related to underlying differences in metabolism, diet, and/or energy regulation which may have affected steroid production. The impact of these factors on steroid production and excretion has also been recorded in other species (von der Ohe and Servheen 2002; Hajamor et al. 2003; Goymann 2005). Moreover, GCs are linked to energy regulation (Romero et al. 2009), so that the major energetic differences between wild and feral individuals could explain the difference recorded in HCCs. Essentially, there is a complex network of interactions between GCs, steroids, and metabolic hormones which means that disturbances in this web may produce a cascade effect on other physiological systems (Fanson et al. 2012).

A second explanation might be related to differing degrees of tolerance of each subspecies toward anthropic disturbance or towards other con(sub)specifics. Feral cats are known to live in close contact with humans (and each other), although only in relation to foraging behaviour (Natoli 1994). In this sense, they may be more tolerant toward humans and intraspecific presence than wild individuals. Anecdotal evidence suggests some "feral" cats behave as wildcats. An animal closely resembling a wildcat or a hybrid currently (August 2019, and since at least 2011) lives in a "wild" setting, amongst rocks in woodland beneath a road close to a village in the Italian Karst (in an area where true wildcats are present). Only 50 metres from the nearest houses, it does not frequent the feral cat colony less than 75 metres from its earth and has never been observed feeding on food put out for these animals, even in cold weather (Paul Tout, pers. comm.). The Friuli Venezia Giulia Region is characterized by a marked anthropic influence due to the presence of infrastructure across much of its surface area, leading to a reduction in the ecological value of each area affected (Angelini et al. 2009). Consequently, wildcats are forced to live in areas with less suitable or unsuitable habitats. Our results showed that, based on the average PLAND value calculated within each buffer, the habitat was composed of a notable percentage of both agricultural $(34.95 \%)$ and built-up areas $(16.67 \%)$ which, as reported by Lozano et al. (2003, 2010), Sarmento et al. (2006), and Klar et al. (2008) are considered as less suitable or unsuitable habitat for the wildcat. What is more, the average IAP calculated within each buffer showed that the area was influenced by a marked anthropic pressure, which may have affected individual wildcat welfare. The effect of anthropic disturbance on cortisol accumulation has received considerable attention in recent years and has been studied in various species (Rangel-Negrín et al. 2009; Zwijacz-Kozica et al. 2012; Burbonnais et al. 2013; Creel et al. 2013; Deng et al. 2014; Fourie et al. 2015) including tigers (Naidenko et al. 2019) and wildcats (Piñeiro et al. 2012). For instance, Naidenko et al. (2019) compared faecal glucocorticoid levels between two tiger subspecies, the Amur tiger and Bengal tiger living in two extreme habitats. From the analysis, they recorded that FCMs were significantly higher in Bengal tigers living in India than in Amur tigers living in the Russian Far East and, as explained by the authors, these reasons might be related to tiger density or anthropogenic disturbance. A further study performed by Rangel-Negrín et al. (2009) showed that forest fragmentation may create long-term stressors for spider monkeys (Ateles geoffroyi yucatanensis) affecting population viabilities. Deng et al. (2014) revealed a significant positive correlation between FCM levels recorded in giant pandas (Ailuropoda melanoleuca) and the degree of human disturbance within their habitat. Fourie et al. (2015) showed that human impacts on vervet monkeys' (Chlorocebus aethiops) behavioural ecology appeared to be a significant source of stress, especially for males. Furthermore, it was demonstrated that even tourism may exert a negative effect on animal 
welfare. Zwijacz-Kozica et al. (2012), studying the concentration of FCMs in chamois (Rupicapra rupicapra) in relation to tourist pressure in Tatra National Park (South Poland), showed that stress levels increased in relation to increasing numbers of visitors, exhibiting a peak during the summer months in areas where tourists were common. The same result was obtained by Piñeiro et al. (2012) measuring cortisol metabolites in fresh wildcat faecal samples within the Natural Park Montes do Invernadeiro (north-western Spain). From their study, they showed that cortisol metabolite concentrations were higher in certain park areas where tourism intensity was higher.

A third explanation may be related to differences in terms of environmental pressures to which each subspecies was subjected. For instance, Naidenko et al. (2011) compared cortisol levels between wild and captive Amur tigers, showing that wild tigers had significantly higher cortisol concentrations compared to captive ones and that the reason might be related to the unfavourable influences of low temperatures and deep snow cover. As the feral cats lived in colonies in close contact with human beings who regularly supplied them with food, they were not subjected to stressors (i.e. hunting for food) which might have led to increased HPA gland axis activity. Moreover, factors such as interspecific and intraspecific competition might have affected individual wildcats' welfare resulting in higher hair cortisol accumulations. In Friuli Venezia Giulia, the main medium-sized carnivores which may compete with the wildcat for territory and/or food resources are the beech marten (Martes foina), the pine marten (Martes martes), the red fox (Vulpes vulpes), and the golden jackal (Canis aureus). However, research focused on assessing the impact of interspecific competition on wildcat welfare is still rather sparse. To the best of our knowledge, the only study carried was that by Piñeiro et al. (2015) in which FCM levels in a free-living population of wildcats in northwest Spain were analyzed and showed that the presence of competitors such as pine martens and red foxes did not significantly affect cortisol concentration. As reported by the authors, the absence of a significant effect in relation to red fox presence may be attributable to the generalist behaviour of that species, both in terms of diet (Jędrzejewski and Jędrzejewska 1992) and habitat selection (Lucherini et al. 1995), with subsequently reduced competition. As far as the presence of pine martens is concerned, despite no significant effects being detected, the authors showed that there was a trend for raised cortisol levels measured in wildcats living in habitat selected by the pine marten (i.e. pine forests and shrublands).

Here we encounter a potential explanation for the difference in terms of cortisol levels recorded between wild and feral cats, thus corroborating our hypothesis. Nevertheless, there might be further ecological and physiological factors (e.g. individuals' health status or pregnancy condition) not considered in the current study which could affect HPA gland axis activity in both subspecies.

\subsection{Hair cortisol levels comparison between sexes in wild and feral individuals}

No significant difference between sexes was found in either wild or feral individuals. In general, males showed higher cortisol levels than females and this difference was more evident in wild individuals (mean $\pm \mathrm{sd}=9.69 \pm 4.81 \mathrm{pg}$ cortisol/mg hair for males; mean $\pm \mathrm{sd}=6.78 \pm 2.87 \mathrm{pg}$ cortisol $/ \mathrm{mg}$ hair for females) than in feral ones ( $\mathrm{mean} \pm \mathrm{sd}=$ $3.76 \pm 1.33 \mathrm{pg}$ cortisol/mg hair for males; mean $\pm \mathrm{sd}=2.81 \pm 0.50 \mathrm{pg}$ cortisol/mg hair for females). Sex differences in cortisol accumulation have been documented in felids (Brown and Wildt 1997; Narayan et al. 2013; Cattet et al. 2014) highlighting the underlying differences in steroid metabolism, excretion routes, and HPA gland axis responses (Goymann 2012). For instance, Narayan et al. (2013) observed a significant difference in terms of FCMs in two captive populations of Bengal and Sumatran tigers. Following the authors, this difference might be due to the females' reproductive hormone cycle (i.e. oestrogen and progesterone) which could have affected the expression of FCMs (Palme et al. 2005). Hair cortisol comparison between sexes has also been identified in other mammal taxa (Dantzer et al. 2010; Creel et al. 2013; Bryan et al. 2014; Lafferty et al. 2015) but the results obtained were sometimes 
controversial. For example, Bryan et al. (2014) found no significant differences in HCCs between sexes in American black bears (Ursus americanus) and/or grizzly bears (Ursus arctos horribilis), Creel et al. (2013) found that male lions had higher faecal cortisol metabolite levels than females. On the contrary, Dantzer et al. (2010), comparing faecal glucocorticoids levels between sexes in North American red squirrels (Tamiasciurus hudsonicus), showed that females exhibited higher cortisol levels than males. Conflicting results among studies suggest that multiple factors may thus contribute to the observed sex-based difference in stress hormone levels. For example, intraspecific dominance and competition among males may induce a stress situation, but reproduction also seems to play a key role. Adrenal activity has been shown to vary with female reproductive status in different species. In fact, pregnant females have significantly higher levels of GCs than non-pregnant ones (Ziegler and Snowdon 1995; Gardiner and Hall 1997; Cavigelli 1999; Weingrill et al. 2004; Dantzer et al. 2010; Fanson et al. 2012). Gardiner and Hall (1997) obtained a significant difference in plasma cortisol concentrations between males and females in harbour seal (Phoca vitulina) within the reproductive period. Weingrill et al. (2004) observed that faecal cortisol levels in free-ranging female chacma baboons (Papio hamadryas ursinus) were significantly higher in females than in males. Dantzer et al. (2010) showed that a reproduction-related condition (i.e. pregnancy, lactation, post-lactation) significantly affected FCM levels in freeranging female North American red squirrels. Fanson et al. (2012) observed that males and females in Canada lynx showed differing seasonal pattern in FGM concentrations. In males, FCMs peaked during the breeding season and then decreased during summer. Conversely, FCMs in females were lower in winter/early spring and increased toward the end of the breeding season. Thus, in general, the increased metabolic demands associated with reproduction could be driving GC concentrations during reproductive phases (Cavigelli 1999; Goymann et al. 1999; Palme et al. 2003) leading to higher cortisol concentrations in females. In our case, we did not know the reproductive status of each female monitored as no hormonal analysis was performed. However, no evident signs of reproduction were detected. To sum up, therefore, we could say that the difference in cortisol secretion between males and females might be related to both physiological and individual behavioural characteristics.

\section{Conclusions}

The results presented in this study revealed that wildcats showed significantly higher HCCs than feral individuals, and no significant difference in terms of cortisol levels were obtained between sexes in either population. We are aware that this research presents some limitations in terms of reduced sample size, lack of information regarding the individuals' health and reproductive status and the higher number of males sampled compared to females in both groups, which may have biased the lack of significance of some results achieved. Nevertheless, despite such limitations, this is the first time in which hair cortisol levels have been compared between wild and feral cats, thus increasing the limited information available regarding the physiological response of felids exposed to different environmental pressures. The findings presented may thus contribute to laying the foundation for future works focused in assessing the various physiological and ecological factors affecting the HPA gland axis activity of those populations living under a range of environmental conditions, thus leading to the establishment of adequate conservation plans toward those species (or subspecies) which are classified as endangered or critically endangered.

\section{References}

Accorsi PA, Carloni E, Valsecchi P, Viaggaini R, Gamberoni M, Tamanini C, Seren E (2008) Cortisol determination in hair and faeces from domestic cats and dogs. Gen Comp Endocrinol 155:398-402. doi: 
10.1016/j.ygcen.2007.07.002

Angelini P, Augello R, Bagnaia R, Bianco P, Capogrossi R, Cardillo A, Ercole S, Francescato C, Giacanelli V, Laureti L, Lugeri F, Lugeri N, Novellino E, Oriolo G, Papallo O, Serra B (2009) Il Progetto Carta della Natura. Linee $\begin{array}{llllllll}\text { guida per la cartografia e la valutazione degli habitat alla scala } & 1: 50.000\end{array}$ http://www.isprambiente.gov.it/files/carta-della-natura/cdn-manuale.pdf

Anile S, Bizzarri L, Lacrimini M, Sforzi A, Ragni B, Devillard S (2017) Home-range size of the European wildcat (Felis silvestris silvestris): a report from two areas in Central Italy. Mammalia 82(1):1-11. doi: 10.1515/mammalia-2016-0045

Apostolico F, Vercillo F, La Porta G, Ragni B (2016) Long-term changes in diet and trophic niche of the European wildcat (Felis silvestris silvestris) in Italy. Mammal Res 61:109-119. doi: 10.1007/s13364-015-0255-8

Ashley NT, Barboza PS, Macbeth BJ, Janz DM, Cattet MRL, Both RK, Wasser SK (2011) Glucocorticosteroid concentrations in feces and hair of captive caribou and reindeer following adrenocorticotropic hormone challenge. Gen Comp Endocrinol 172:382-391. doi: 10.1016/j.ygcen.2011.03.029

Balíková M (2005) Hair analysis for drugs of abuse. Plausibility of interpretation. Biomed Pap Med Fac Univ Palacky Olomouc Czech Repub 149:199-207. doi: 10.5507/bp.2005.026

Ballesteros-Duperón E, Virgós E, Moleón M, Barea-Azcón JM, Gil-Sánchez JM (2015) How accurate are coat traits for discriminating wild and hybrid forms of Felis silvestris? Mammalia 79:101-110. doi: 10.1515/mammalia-20130026

Barja I, Silván G, Rosellini S, Piñeiro A, González-Gil A, Camacho L, Illera JC (2007) Stress physiological responses to tourist pressure in a wild population of European pine marten. J Steroid Biochem Mol Biol 104:136-142. doi: 10.1016/j.jsbmb.2007.03.008

Bayazit V (2009) Evaluation of Cortisol and Stress in Captive Animal. Aust J Basic Appl Sci 3:1022-1031. https://pdfs.semanticscholar.org/3f05/c6638addc7dcaa243cf74061969a9fca3854.pdf

Bechshøft TØ, Derocher AE, Richardson E, Mislan P, Lunn NJ, Sonne C, Dietz R, Janz DM, St Louis VL (2015) Mercury and cortisol in Western Hudson Bay polar bear hair. Ecotoxicology 24:1315-1321. doi: 10.1007/s10646015-1506-9

Bechshøft TØ, Rigét FF, Sonne C, Letcher RJ, Muir DCG, Novak MA, Henchey E, Meyer JS, Eulaers I, Jaspers VLB, Eens M, Covaci A, Dietz R (2012) Measuring environmental stress in East Greenland polar bears, 1892-1927 and 1988-2009: What does hair cortisol tell us? Environ Int 45:15-21. doi: 10.1016/j.envint.2012.04.005

Bechshøft TØ, Sonne C, Dietz R, Born EW, Novak MA, Henchey E, Meyer JS (2011) Cortisol levels in hair of East Greenland polar bears. Sci Total Environ 409:831-834. doi: 10.1016/j.scitotenv.2010.10.047

Berger EM, Leus K, Vercammen P, Schwarzenberger F (2006) Faecal steroid metabolites for non-invasive assessment of reproduction in common warthogs (Phacochoerus africanus), red river hogs (Potamochoerus porcus) and babirusa (Babyrousa babyrussa). Anim Reprod Sci 91:155-171. doi: 10.1016/j.anireprosci.2005.03.009

Boonstra R (2004) Coping with Changing Northern Environments: The Role of the Stress Axis in Birds and Mammals. Integr Comp Biol 44:95-108. doi: 10.1093/icb/44.2.95

Burbonnais ML, Nelson TA, Cattet MR, Darimont CT, Stenhouse GB (2013) Spatial Analysis of Factors Influencing Long-Term Stress in the Grizzly Bear (Ursus arctos) Population of Alberta, Canada. PLoS ONE 8(12):e83768. doi: $10.1371 /$ journal.pone.0083768

Brown JL, Wildt DE (1997) Assessing reproductive status in wild felids by non-invasive faecal steroid monitoring. Int Zoo Yh 35:173-191 doi: 10.1111/j.1748-1090.1997.tb01208.x 
Bryan HM, Darimont CT, Paquet PC, Wynne-Edwards KE, Smits JEG (2014) Stress and reproductive hormones reflect inter-specific social and nutritional conditions mediated by resource availability in a bear-salmon system. Conserv Physiol 2:1-18. doi: 10.1093/conphys/cou010

Carta della Natura del Friuli Venezia Giulia (2007). Retrieved 27 February 2019 from http://irdat.regione.fvg.it/WebGIS/.

Caslini C, Comin A, Peric T, Prandi A, Pedrotti L, Mattiello S (2016) Use of hair cortisol analysis for comparing population status in wild red deer (Cervus elaphus) living in areas with different characteristics. Eur J Wildl Res 62:713-723. doi: 10.1007/s10344-016-1049-2

Cattet M, Macbeth BJ, Janz DM, Zedrosser A, Swenson JE, Dumond M, Stenhouse GB (2014) Quantifying long-term stress in brown bears with the hair cortisol concentration: a biomarker that may be confounded by rapid changes in response to capture and handling. Conserv Physiol 2:1-15. doi: 10.1093/conphys/cou026

Cavigelli SA (1999) Behavioural patterns associated with faecal cortisol levels in free-ranging female ring-tailed lemurs, Lemur catta. Anim Behav 57:935-944. doi: 10.1006/anbe.1998.1054

Comin A, Peric T, Magrin L, Corazzin M, Cornacchia G, Prandi A (2014) Study of progesterone and cortisol concentrations in the Italian Friesian claw. J Dairy Sci 97:5491-5496. doi: 10.3168/jds.2014-7943

Comin A, Peric T, Corazzin M, Veronesi MC, Meloni T, Zufferli V, Cornacchia G, Prandi A (2013) Hair cortisol as a marker of hypothalamic-pituitary-adrenal axis activation in Friesian dairy cows clinically or physiologically compromised. Livest Sci 152:36-41. doi: 10.1016/j.livsci.2012.11.021

Comin A, Prandi A, Peric T, Corazzin M, Dovier S, Bovolenta S (2011) Hair cortisol levels in dairy cows from winter housing to summer highland grazing. Livest Sci 138:69-73. doi: 10.1016/j.livsci.2010.12.009

Creel S, Christianson D, Schuette P (2013) Glucocorticoid stress responses of lions in relationship to group composition, human land use, and proximity to people. Conserv Physiol 1:1-9. doi: 10.1093/conphys/cot021

Dantzer B, McAdam AG, Palme R, Fletcher QE, Boutin S, Humphries MM, Boonstra R (2010) Fecal cortisol metabolite levels in free-ranging North American red squirrels: Assay validation and the effects of reproductive condition. Gen Comp Endocrinol 167:279-286. doi: 10.1016/j.ygcen.2010.03.024

Darlingtont DN, Chew G, Ha T, Keil LC, Dallman MF (1990) Corticosterone, but not Glucose, Treatment Enables Fasted Adrenalectomized Rats to Survive Moderate Hemorrhage. Endocrinology 127(2):766-772. doi: 10.1210/endo-127-2-766

Davenport MD, Tiefenbacher S, Lutz CK, Novak MA, Meyer JS (2006) Analysis of endogenous cortisol concentrations in the hair of rhesus macaques. Gen Comp Endocrinol 147:255-261. doi: 10.1016/j.ygcen.2006.01.005

David M, Auclair Y, Cézilly F (2011) Personality predicts social dominance in female zebra finches, Taeniopygia guttata, in a feeding context. Anim Behav 81:219-224. doi: 10.1016/j.anbehav.2010.10.008

Dehnhard M, Clauss M, Lechner-Doll M, Meyer HHD, Palme R (2001) Noninvasive monitoring of adrenocortical activity in roe deer (Capreolus capreolus) by measurement of fecal cortisol metabolites. Gen Comp Endocrinol 123:111-120. doi: 10.1006/gcen.2001.7656

Deng H, Jin X, Hn D (2014) Fecal cortisol content of wild giant pandas (Ailuropoda melanoleuca) to monitor human disturbance level in natural habitats. 64:75-86. doi: 10.1163/15707563-00002432

Dingemanse NJ, Réale D (2005) Natural selection and animal personality. Behaviour 142:1159-1184. doi: $10.1163 / 156853905774539445$

Driscoll C, Nowell K (2010) Felis silvestris. The IUCN Red List of Threatened Species. Version 2014.2. http://www.iucnredlist.org/details/8543/0. Accessed on 04 November 2019 
Fanson KW, Wielebnowski NC, Shenk TM, Lucas JR (2012) Comparative patterns of adrenal activity in captive and wild Canada lynx (Lynx canadensis). J Comp Physiol B 182:157-165. doi: 10.1007/s00360-011-0597-8

Fourie NH, Turner TR, Brown JL, Pampush JD, Lorenz JG, Bernstein RM (2015) Variation in vervet (Chlorocebus aethiops) hair cortisol concentrations reflects ecological disturbance by humans. Primates 56:365-373. doi: 10.1007/s10329-015-0486-y

Gardiner KJ, Hall AJ (1997) Diel and annual variation in plasma cortisol concentrations among wild and captive harbor seals (Phoca vitulina). Can J Zool 75:1773-1780. doi: 10.1139/z97-806

Goymann W (2012) On the use of non-invasive hormone research in uncontrolled, natural environments: the problem with sex, diet, metabolic rate and the individual. Methods Ecol Evol 3(4):757-765. doi: 10.1111/j.2041210X.2012.00203.X

Goymann W (2005) Non-invasive Monitoring of Hormones in Bird Droppings Physiological Validation, Sampling, Extraction, Sex Differences, and the Influence of Diet on Hormone Metabolite Levels. Ann NY Acad Sci 1046: 35-53. doi: 10.1196/annals.1343.005

Goymann W, Möstl E, Van't Hof T, East ML, Hofer H (1999) Non-invasive Fecal Monitoring of Glucocorticoids in Spotted Hyenas, Crocuta crocuta. Gen Comp Endocr 114:340-348. doi: 10.1006/gcen.1999.7268

Graham L, Schwarzenberger F, Möstl E, Galama W (2001) A Versatile Enzyme Immunoassay for the Determination of Progestogens in Feces and Serum. Zoo Biol 20:227-236. doi: 10.1002/zoo.1022

Gygax L, Neuffer I, Kaufmann C, Hauser R, Wechsler B (2006) Milk Cortisol Concentration in Automatic Milking Systems Compared with Auto-Tandem Milking Parlors. J Dairy Sci 89:3447-3454. doi: 10.3168/jds.S00220302(06)72382-7

Hajamor S, Despre J, Couillard C, Lemieux S, Tremblay A, Prud'homme D, Tchernof A (2003) Relationship Between Sex Hormone-Binding Globulin Levels and Features of the Metabolic Syndrome. Metabolism 52(6):724-730. doi: 10.1016/S0026-0495(03)00066-0

Hamilton LD, Rellini AH, Meston CM (2008) Cortisol, Sexual Arousal, and Affect in Response to Sexual Stimuli. J Sex Med 5:2111-2118. doi: 10.1111/j.1743-6109.2008.00922.x

Heistermann M, Palme R, Ganswindt A (2006) Comparison of Different Enzymeimmunoassays for Assessment of Adrenocortical Activity in Primates Based on Fecal Analysis. Am J Primatol 68:257-273. doi: 10.1002/ajp

Huber S, Palme R, Arnold W (2003) Effects of season, sex, and sample collection on concentrations of fecal cortisol metabolites in red deer (Cervus elaphus). Gen Comp Endocrinol 130:48-54. doi: 10.1016/S0016-6480(02)00535X

Janczak AM, Pedersen LJ, Bakken M (2003) Aggression, fearfulness and coping styles in female pigs. Appl Anim Behav Sci 81:13-28. doi: 10.1016/S0168-1591(02)00252-6

Jȩdrzejewski W, Jȩdrzejewska B (1992) Foraging and Diet of the Red Fox Vulpes vulpes in Relation to Variable Food Resources in Białowieża National Park, Poland. Ecography 15(2):212-220. doi: 10.1111/j.16000587.1992.tb00027.x

Keay JM, Singh J, Ph D, Gaunt MC (2006) Fecal glucocorticoids and their metabolites as indicators of stress in various mammalian species : A literature review. J Zoo Wildlife Med 37(3): 234-244. doi: 10.1638/05-050.1

Killshaw K (2011) Scottish wildcats. Scottish Natural Heritage Publishing, Battleby.

Kintz P, Villain M, Cirimele V (2006) Hair analysis for drug detection. Ther Drug Monit 28:442-446. doi: 10.1097/01.ftd.0000211811.27558.b5

Klar N, Fernández N, Kramer-Shadt S, Herrmann M, Trinzen M, Büttner I, Niemitz C (2008) Habitat selection models 
for European wildcat conservation. Biol Conserv 141:308-319. doi:10.1016/j.biocon.2007.10.004

Koolhaas JM, Korte SM, De Boer SF, Van Der Vegt BJ, Van Reenen CG, Hopster H, De Jong IC, Ruis MAW, Blokhuis HJ (1999) Coping styles in animal: Current status in behavior and stress-physiology. Neurosci Biobehav Rev 23:925-935. doi: 10.1016/S0149-7634(99)00026-3

Koren L, Mokady O, Karaskov T, Klein J, Koren G, Geffen E (2002) A novel method using hair for determining hormonal levels in wildlife. Anim Behav 63:403-406. doi: 10.1006/anbe.2001.1907

Lafferty DJR, Laudenslager ML, Mowat G, Heard D, Belant JL (2015) Sex, diet, and the social environment: Factors influencing hair cortisol concentration in free-ranging black bears (Ursus americanus). PLoS One 10(11): e0141489. doi: 10.1371/journal.pone.0141489

Lapini L (2006) Attuale Distribuzione del Gatto Selvatico Felis silvestris silvestris Schreber, 1775 nell'Italia NordOrientale (Mammalia: Felidae). Boll Mus civ St nat Venezia 57:221-234. https://www.researchgate.net/profile/Luca_Lapini2/publication/272096191_LAPINI_L_2006_A_Attuale_distribu zione_del_gatto_selvatico_Felis_silvestris_silvestris_SCHREBER_1775_nell'Italia_nordorientale_Mammalia_Felidae_Boll_Mus_civ_St_nat_Venezia_57_221-234/links/54db2b640cf2ba88a68f4f04.pdf

Leboulenger F, Delarue C, Belanger A, Perroteau I, Netchitailo P, Leroux P, Jegou S, Tonon MC, Vaudry H (1982) Direct Radioimmunoassays for Plasma Corticosterone and Aldosterone in Frog. I. Validation of the Methods and Evidence for Daily Rhythms in a Natural Environment. Gen Comp Endocr 46:521-532. doi: 10.1016/00166480(82)90108-3

Lozano J, Malo AF (2012) Conservation of European wildcat (Felis silvestris) in Mediterranean environments: a reassessment of current threats. In: Williams GS (ed) Mediterranean ecosystems: dynamics, management and conservation. Nova Science Publishers, Hauppauge, NY, pp 1-31.

Lozano J (2010) Habitat use by European wildcats (Felis silvestris) in central Spain: what is the relative importance of forest variables? Anim Biodiv 33(2):143-150. https://www.researchgate.net/publication/49592464_Habitat_use_by_European_wildcats_Felis_silvestris_in_cent ral_Spain_what_is_the_relative_importance_of_forest_variables

Lozano J, Virgós E, Malo AF, Huertas DL, Casanovas JG (2003) Importance of scrub-pastureland mosaics for wildliving cats occurrence in a Mediterranean area: implications for the conservation of the wildcat (Felis silvestris). Biodiv Conserv 12: 921-935. doi: 10.1023/A:1022821708594

Lucherini M, Lovari S, Crema G (1995) Habitat use and ranging behaviour of the red fox Vulpes vulpes in a Mediterranean rural area: is shelter availability a key factor? J Zool 237:577-591. doi: 10.1111/j.14697998.1995.tb05016.x

Macbeth BJ, Cattet MRL, Stenhouse GB, Gibeau ML, Janz DM (2010) Hair cortisol concentration as a noninvasive measure of long-term stress in free-ranging grizzly bears (Ursus arctos): considerations with implications for other wildlife. Can J Zool 88:935-949. doi: 10.1139/Z10-057

Mattucci F, Oliveira R, Bizzarri L, Vercillo F, Anile S, Ragni B, Lapini L, Sforzi A, Alves PC, Lyons LA, Randi E (2013) Genetic structure of wildcat (Felis silvestris) populations in Italy. Ecol Evol 3:2443-2458. doi: $10.1002 /$ ece 3.569

Millspaugh JJ, Washburn BE, Milanick MA, Beringer J, Hansen LP, Meyer TM (2002) Non-Invasive Techniques for Stress Assessment in White-Tailed Deer. Source Wildl Soc Bull 30(3):899-907. doi: 10.2307/3784245

Montiglio PO, Garant D, Pelletier F, Réale D (2012) Personality differences are related to long-term stress reactivity in a population of wild eastern chipmunks, Tamias striatus. Anim Behav 84:1071-1079. doi: 
10.1016/j.anbehav.2012.08.010

Mormède P, Andanson S, Aupérin B, Beerda B, Guémené D, Malmkvist J, Manteca X, Manteuffel G, Prunet P, van Reenen CG, Richard S, Vaissier I (2007) Exploration of the hypothalamic-pituitary-adrenal function as a tool to evaluate animal welfare. Physiol Behav 92:317-339. doi: 10.1016/j.physbeh.2006.12.003

Möstl E, Palme R (2002) Hormones as indicators of stress. Domest Anim Endocrinol 23:67-74. doi: 10.1016/S07397240(02)00146-7

Naidenko SV, Berezhnoi MA, Kumar V, Umapathy G (2019) Comparison of tigers' fecal glucocorticoids level in two extreme habitats. PLoS ONE 14(4): e0214447. doi: 10.1371/journal.pone.0214447

Naidenko SV, Ivanov EA, Lukarevskii VS, Hernandez-Balnco JA, Sorokin PA, Litvinov MN, Kotlyar AK, Rozhnov VV (2011) Activity of the Hypothalamic-Pituitary-Adrenal Axis in the Siberian Tiger (Panthera tigris altaica) in Captivity and in The Wild, and Its Dynamics throughout the Year. Biol Bull Russ Acad Sci 38(3):301-305. doi: $10.1134 / \mathrm{S} 1062359011030095$

Narayan EJ, Parnell T, Clark G, Martin-Vegue P, Mucci A, Hero JM (2013) Faecal cortisol metabolites in Bengal (Panthera tigris tigris) and Sumatran tigers (Panthera tigris sumatrae). Gen Comp Endocr 194:318-325. doi: 10.1016/j.ygcen.2013.10.002

Natoli E, Say L, Cafazzo S, Bonanni R, Schmidt M, Pontier D (2005) Bold attitude makes male urban feral domestic cats more vulnerable to Feline Immunodeficiency Virus. Neurosci Biobehav Rev 29:151-157. doi: 10.1016/j.neubiorev.2004.06.011

Natoli E (1994) Urban feral cats (Felis catus L.): perspectives for a demographic control respecting the psychobiological welfare of the species. Ann 1st Super Sanità 30(2):223-227. https://www.researchgate.net/profile/Eugenia_Natoli/publication/15367635_Urban_feral_cats_Felis_catus_L_per spectives_for_a_demographic_control_respecting_the_psychobiological_welfare_of_the_species/links/55117cb20cf21209d528a8ae.pdf

Negrão JA, Porcionato MA, de Passillé AM, Rushen J (2004) Cortisol in Saliva and Plasma of Cattle After ACTH Administration and Milking. J Dairy Sci 87:1713-1718. doi: 10.3168/jds.S0022-0302(04)73324-X

Official site of Friuli Venezia Giulia region - English Version (n.d.). Retrived 28 February 2019 from http://www.regione.fvg.it/inglese/pagine_interne/welcome_history.asp.

Palme R, Rettenbacher S, Touma C, El-Bahr SM, Möstl E (2005) Comparative Aspects Regarding Metabolism, Excretion, and Noninvasive Measurement in Faecal Samples. Ann NY Acad Sci 1040:162-171. doi: 10.1196/annals.1327.021

Palme R (2005) Measuring fecal steroids: Guidelines for practical application. Ann N Y Acad Sci 1040:75-80. doi: 10.1196/annals.1343.007

Palme R, Touma C, Sachser N, Erich M (2003) Effects of sex and time of day on metabolism and excretion of corticosterone in urine and feces of mice. 130:267-278. doi: 10.1016/S0016-6480(02)00620-2

Palme R, Fisher P, Schildorfer H, Ismail MN (1996) Excretion of infused 14C-steroid hormones via faeces and urine in domestic livestock. Anim Reprod Sci 43:43-46. doi: 10.1016/0378-4320(95)01458-6

Peric T, Comin A, Corazzin M, Montillo M, Canavese F, Stebel M, Prandi A (2018) Hair cortisol concentrations in New Zealand white rabbits subjected to surgery. Anim Welfare 27:13-20. doi: 10.7120/09627286.27.1.013

Peric T, Corazzin M, Romanzin A, Bovolenta S, Prandi A, Montillo M, Comin A (2017) Cortisol and DHEA concentrations in the hair of dairy cows managed indoor or on pasture. Livest Sci 202:39-43. doi: 10.1016/j.livsci.2017.05.020 
Peric T, Comin A, Corazzin M, Montillo M, Canavese F, Stebel M, Prandi A (2016) Relocation and Hair Cortisol Concentrations in New Zealand White Rabbits. J Appl Anim Welf Sci 20(1):1-8. doi: 10.1080/10888705.2016.1183489

Piñeiro A, Barja I, Otero GP, Silván G, Illera JC (2015). No effects of habitat, prey abundance and competitor carnivore abundance on faecal cortisol metabolite levels in wildcats (Felis silvestris). Ann Zool Fennici 52:90-102. doi: $10.5735 / 086.052 .0208$

Piñeiro A, Bárja I, Silvn G, Illera JC (2012) Effects of tourist pressure and reproduction on physiological stress response in wildcats: Management implications for species conservation. Wildl Res 39:532-539. doi: 10.1071/WR10218

Pragst F, Balikova MA (2006) State of the art in hair analysis for detection of drug and alcohol abuse. Clin Chim Acta 370:17-49. doi: 10.1016/j.cca.2006.02.019

Prandi A, Peric T, Corazzin M, Comin A, Colitti M (2018) A first survey on hair cortisol of an Alpine ibex (Capra ibex ibex) population. Anim Sci Pap $\quad$ Rep 36(1):57-74. https://www.researchgate.net/publication/323705058_A_first_survey_on_hair_cortisol_of_an_alpine_ibex_Capra _ibex_ibex_population

Ragni B, Possenti M (1996) Variability of coat-colour and markings system in Felis silvestris. Ital J Zool 63:285-292. doi: 10.1080/11250009609356146

Rangel-Negrín A, Alfaro JL, Valdez RA, Romano MC, Serio-Silva JC (2009) Stress in Yucatan spider monkeys: Effects of environmental conditions on fecal cortisol levels in wild and captive populations. Anim Conserv 12:496-502. doi: 10.1111/j.1469-1795.2009.00280.x

Rehbinder C, Hau J (2006) Quantification of cortisol, cortisol immunoreactive metabolites, and immunoglobulin A in serum, saliva, urine, and feces for non-invasive assessment of stress in reindeer. Can J Vet Res 70:151-154. https://www.researchgate.net/publication/7141019_Quantification_of_cortisol_cortisol_immunoreactive_metabol ites_and_immunoglobulin_A_in_serum_saliva_urine_and_feces_for_noninvasive_assessment_of_stress_in_reind eer

Romero LM, Dickens MJ, Cyr NE (2009) Hormones and Behavior The reactive scope model - A new model integrating homeostasis, allostasis, and stress. Horm Behav 55:375-389. doi: 10.1016/j.yhbeh.2008.12.009

Romero LM (2004) Physiological stress in ecology: Lessons from biomedical research. Trends Ecol Evol 19:249-255. doi: $10.1016 /$ j.tree.2004.03.008

Romero LM (2002) Seasonal changes in plasma glucocorticoid concentrations in free-living vertebrates. Gen Comp Endocr 128:1-24. doi: 10.1016/S0016-6480(02)00064-3

Romero LM, Wingfield JC (2001) Regulation of the hypothalamic-pituitary-adrenal axis in free-living pigeons. J Comp Physiol B 171:231-235. doi: 10.1007/s003600000167

Roth TL, Brien JKO, Mcrae MA, Bellem AC, Romo SJ, Kroll JL, Brown JL (2001) Ultrasound and endocrine evaluation of the ovarian cycle and early pregnancy in the Sumatran rhinoceros, Dicerorhinus sumatrensis. Reproduction 121:139-149. doi: 10.1530/reprod/121.1.139

Ruiz-Gomez MDL, Huntingford FA, Øverli Ø, Thörnqvist PO, Höglund E (2011) Response to environmental change in rainbow trout selected for divergent stress coping styles. Physiol Behav 102:317-322. doi: 10.1016/j.physbeh.2010.11.023

Russell E, Koren G, Rieder M, Van Uum S (2012) Hair cortisol as a biological marker of chronic stress: Current status, future directions and unanswered questions. Psychoneuroendocrinology 37:589-601. doi: 
10.1016/j.psyneuen.2011.09.009

Sapolsky RM, Romero LM, Munck AU (2000) How Do Glucocorticoids Influence Stress Responses? Preparative Actions. Endocr Rev 21:55-89. doi: 10.1210/er.21.1.55

Sarmento P, Cruz J, Tarroso P, Fonseca C (2006) Space and Habitat Selection by Female European Wild Cats (Felis silvestris silvestris). Wildl Biol Pract 2(2):79-89. doi:10.2461/wbp.2006.2.10

Schatz S, Palme R (2001) Measurement of Faecal Cortisol Metabolites in Cats and Dogs: A Non-invasive Method for Evaluating Adrenocortical Function. Vet Res Commun 25:271-287. doi: 10.1023/A:1010626608498

Schell CJ, Young JK, Lonsdorf EV, Mateo JM, Santymire RM (2017) Investigation of techniques to measure cortisol and testosterone concentrations in coyote hair. Zoo Biol 36:220-225. doi: 10.1002/zoo.21359

Schwarzenberger F (2007) The many uses of non-invasive faecal steroid monitoring in zoo and wildlife species. Int Zoo Yb 41: 52-74. doi: 10.1111/j.1748-1090.2007.00017.x

Schwarzenberger F, Palme R, Bamberg E, Möstl E (1997) A review of faecal progesterone metabolite analysis for noninvasive monitoring of reproductive function in mammals. Int $J$ Mamm Biol 62:214-221. https://www.researchgate.net/publication/266084067_A_review_of_faecal_progesterone_metabolite_analysis_for _non-invasive_monitoring_of_reproductive_function_in_mammals

Schwarzenberger F, Möstl E, Palme R (1996) Faecal steroid analysis for non-invasive monitor of reproductive status in farm, wild and zoo animals. Anim Reprod Sci 42:515-526. doi: 10.1016/0378-4320(96)01561-8

Sheriff MJ, Dantzer B, Delehanty B, Palme R, Boonstra R (2011) Measuring stress in wildlife: Techniques for quantifying glucocorticoids. Oecologia 166:869-887. doi: 10.1007/s00442-011-1943-y

Stradaioli G, Peric T, Montillo M, Comin A, Corazzin M, Veronesi MC, Prandi A (2017) Hair cortisol and testosterone concentrations and semen production of Bos taurus bulls. Ital J Anim Sci 16(4):631-639. doi: 10.1080/1828051X.2017.1303339

von der Ohe CG, Servheen C (2002) Measuring stress in mammals using fecal glucocorticoids : opportunities and challenges. Wildlife Soc B 30(4):1215-1225. https://www.jstor.org/stable/pdf/3784291.pdf

Webb E, Thomson S, Nelson A, White C, Koren G, Rieder M, Van Uum S (2010) Assessing individual systemic stress through cortisol analysis of archaeological hair. J Archaeol Sci 37:807-812. doi: 10.1016/j.jas.2009.11.010

Weingrill T, Gray DA, Barrett L, Henzi SP (2004) Fecal cortisol levels in free-ranging female chacma baboons: relationship to dominance, reproductive state and environmental factors. Horm Behav 45:259-269. doi: 10.1016/j.yhbeh.2003.12.004

Weisser JJ, Hansen M, Björklund E, Sonne C, Dietz R, Styrishave B (2016) A novel method for analysing key corticosteroids in polar bear (Ursus maritimus) hair using liquid chromatography tandem massspectrometry. $\mathrm{J}$ Chromatogr B 1017-1018:45-51. doi: 10.1016/j.jchromb.2016.02.029

Wielebnowski and Watters (2007) Applying Faecal Endocrine Monitoring to Conservation and Behavior Studies of Wild Mammals: Important Considerations and Preliminary Tests. Isr J Ecol Evol 53:439-460. doi: 10.1560/IJEE.53.3.439

Wikelski M, Cooke SJ (2006) Conservation physiology. Trends Ecol Evol 21:38-46. doi: 10.1016/j.tree.2005.10.018

Yamaguchi N, Kitchener A, Driscoll C, Nussberger B (2015) Felis silvestris. IUCN Red List Threat Species 2015 8235:e.T60354712A50652361. doi: 10.2305/IUCN.UK.2015-2.RLTS.T60354712A50652361.en

Young KM, Walker SL, Lanthier C, Waddell WT, Monfort SL, Brown JL (2004) Noninvasive monitoring of adrenocortical activity in carnivores by fecal glucocorticoid analysis. Gen Comp Endocrinol 137:148-165. doi: 10.1016/j.ygcen.2004.02.016 
681 Ziegler TE, Snowdon CT (1995) The Relationship of Cortisol Levels to Social Environment and Reproductive 682 Functioning in Female Cotton-Top Tamarins, Saguinus oedipus. Horm Behav 29:407-424. doi: 10.1006/hbeh.1995.1028

684 Zuur AF, Ieno EN, Walker NJ, Saveliev AA, Smith GM (2009) Mixed effects models and extensions in ecology with R. 685 New York, NY: Springer.

686 Zwijacz-Kozica T, Selva N, Barja I, Silván G, Martínez-Fernández L, Illera JC, Jodlowski M (2012) Concentration of 687 faecal cortisol metabolites in chamois in relation to tourist pressure in Tatra National Park (South Poland). Acta Theriol 58(2):215-222. doi: 10.1007/s13364-012-0108-7 
Fig1. Location of the study area.

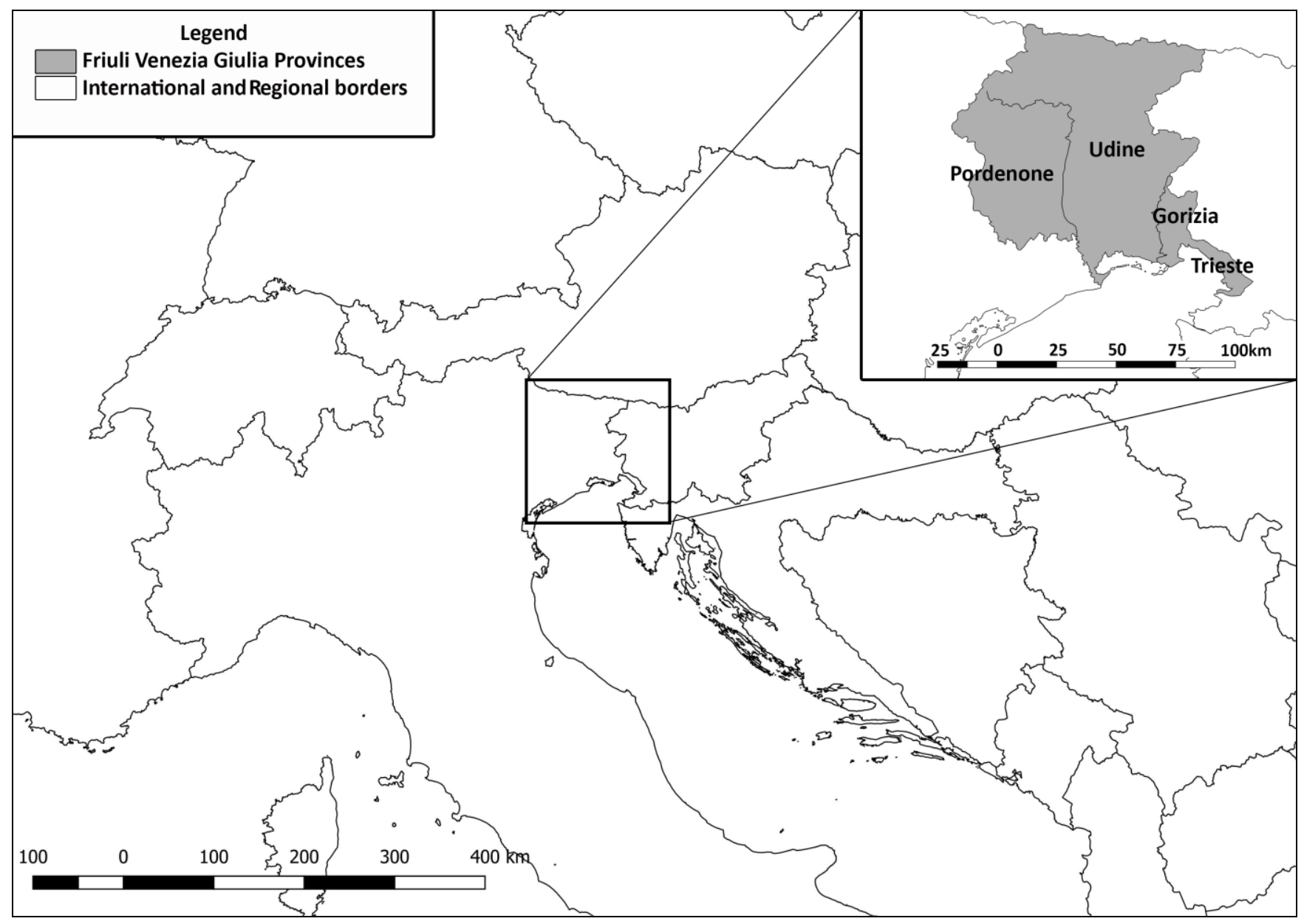


Fig2. Box-plot showing the difference in terms of hair cortisol concentration (pg cortisol/mg hair) between subspecies.

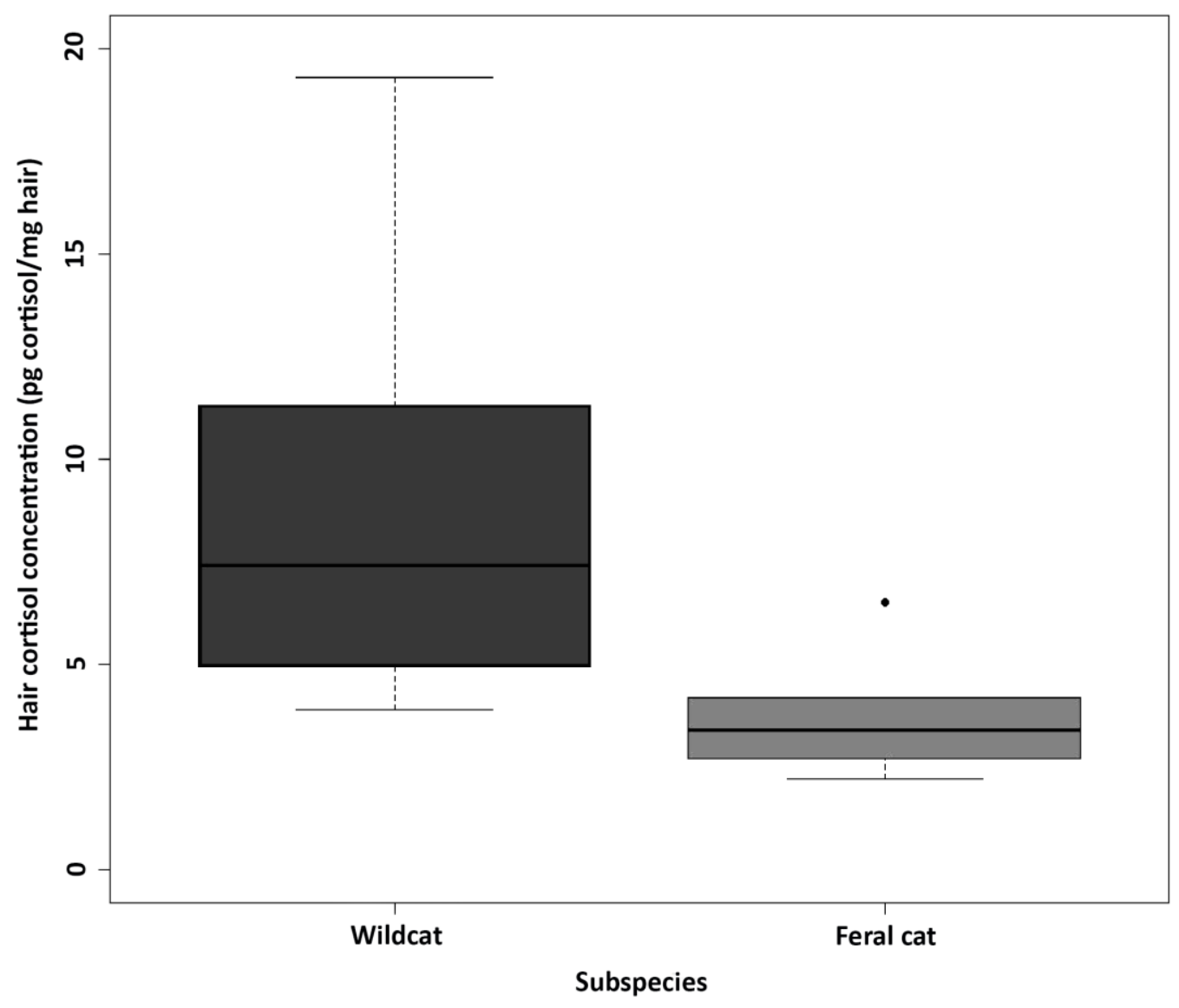


Fig3. Box-plot showing the difference in terms of hair cortisol levels (pg cortisol/mg hair) between sexes in wild (Felis silvestris silvestris) and feral (Felis silvestris catus) cats.
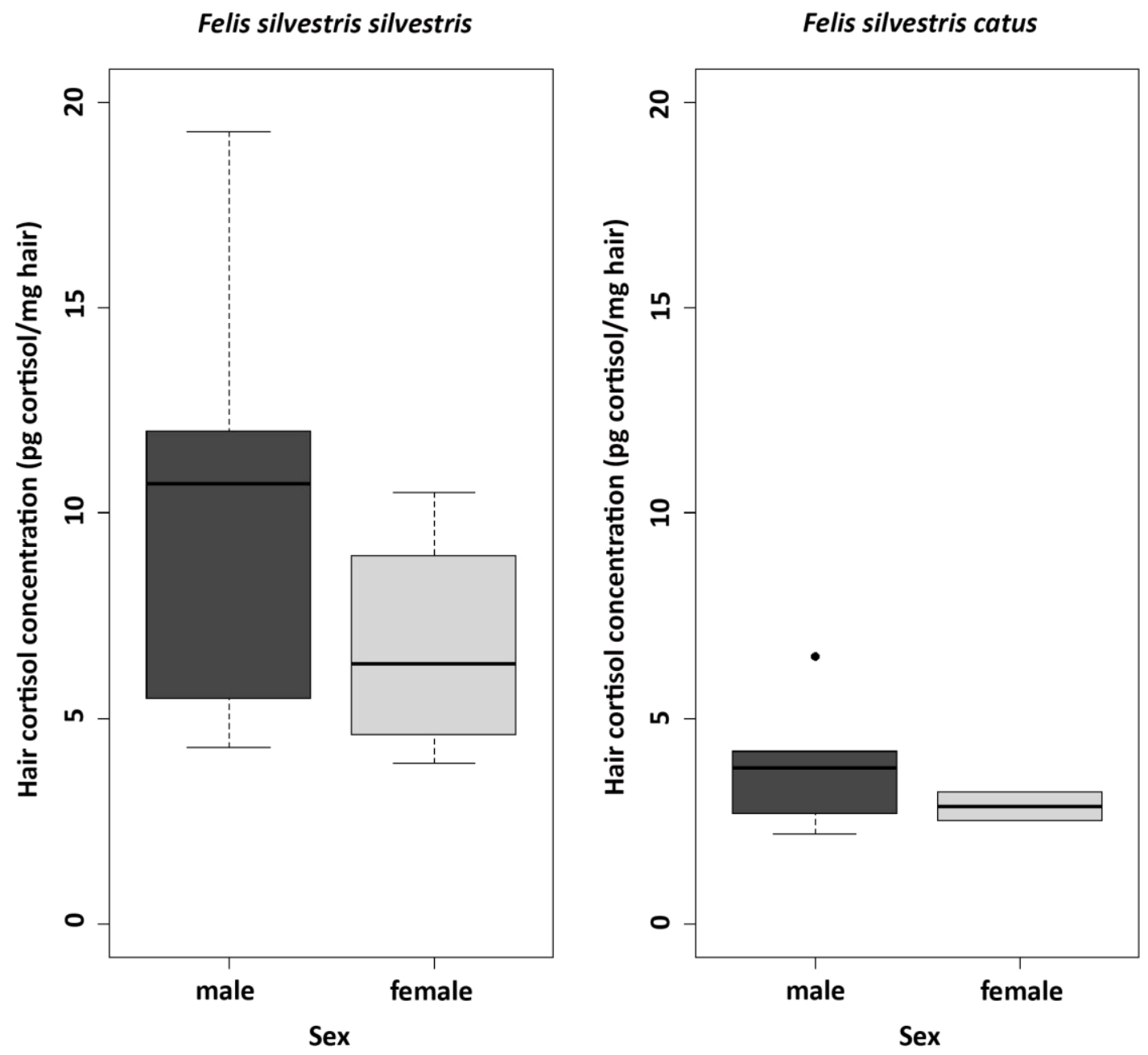
Tab1. Generalized Linear Models (GLMs) ranking with the best model marked in bold. Abbreviations: $K=$ number of parameters; $\log$ Lik =log-likelihood; AICc = Akaike's Information Criterion corrected; $\omega i=$ Akaike's weight.

\begin{tabular}{ccccccc}
\hline ID model & Independent variables & $K$ & $-2 \operatorname{logLik}$ & AICc & $\Delta$ AICc & $\omega i$ \\
\hline $\mathbf{1}$ & subspecies & $\mathbf{3}$ & $\mathbf{1 1 9 . 0 2}$ & $\mathbf{1 2 6 . 1 6}$ & $\mathbf{0}$ & $\mathbf{0 . 7 0}$ \\
2 & subspecies, sex & 5 & 114.67 & 127.83 & 1.67 & 0.30 \\
3 & subspecies, sex, subspecies:sex & 9 & 108.65 & 138.65 & 12.49 & 0.00 \\
4 & sex & 3 & 138.04 & 145.18 & 19.02 & 0.00 \\
\hline
\end{tabular}

Tab2. Hair cortisol concentration (pg cortisol/mg hair) comparison between subspecies. $\mathrm{n}=$ number of individuals.

\begin{tabular}{cccccc}
\hline Subspecies & $\mathrm{n}$ & $\mathrm{n}(\%)$ & Mean & SD & Median \\
\hline Wildcat & 15 & 60 & 8.91 & 4.48 & 7.40 \\
Feral cat & 10 & 40 & 3.57 & 1.25 & 3.39 \\
\hline
\end{tabular}

Tab3. Hair cortisol levels (pg cortisol/mg hair) comparison between sexes in wild (Felis silvestris silvestris) and feral (Felis silvestris catus) cats. $\mathrm{n}=$ number of individuals.

\begin{tabular}{ccccccc}
\hline Subspecies & Sex & $\mathrm{n}$ & $\mathrm{n}(\%)$ & Mean & SD & Median \\
\hline \multirow{2}{*}{ Felis silvestris silvestris } & Male & 11 & 73.33 & 9.69 & 4.81 & 10.70 \\
& Female & 4 & 26.67 & 6.78 & 2.87 & 6.35 \\
\hline \multirow{2}{*}{ Felis silvestris catus } & Male & 8 & 80 & 3.76 & 1.33 & 3.82 \\
& Female & 2 & 20 & 2.81 & 0.50 & 2.81 \\
\hline
\end{tabular}

